\title{
Relationship between Nursing Students' Clinical Placement Satisfaction, Academic Self-Efficacy and Achievement
}

\author{
Hanan Ahmed Al Sebaee ${ }^{1}$, Enas Mahrous Abdel Aziz ${ }^{2}$, Nadia Taha Mohamed ${ }^{3}$ \\ ${ }^{1}$ Assist. Prof. of Medical Surgical Nursing, ${ }^{2}$ Lecturer of Psychiatric Mental Health Nursing, ${ }^{3}$ Lecturer of \\ Nursing Administration \\ ${ }^{1,2,3}$ Faculty of Nursing-Cairo University- Egypt
}

\begin{abstract}
The establishment of quality clinical experience within a supportive and pedagogically clinical learning environment is a significant concern for nursing educational institutions. The aim of the study was to investigate the relationship between nursing students' clinical placement satisfaction, academic self-efficacy, and achievement. Descriptive correlational longitudinal panel research design was utilized for the study. Nursing students enrolled in different nursing courses and affiliated to Technical Nursing Institute - Cairo University during two consecutive academic years were recruited in this study. Personal data tool, students' satisfaction with clinical placement tool and academic self-efficacy scale were used for data collection. Results: More than two thirds of the students were satisfied with their clinical placement. Statistically significant positive correlation between students' achievement in nursing courses, clinical placement' satisfaction and academic efficacies existed and also, between students' gender and clinical placement' satisfactions. A statistically significant negative correlation was detected between students' age and their levels of academic self-efficacy. Conclusion: Nursing students highlighted negative areas that could be taken into consideration by the faculty members, clinical instructors, and clinical staff to enhance learning in the clinical setting. Satisfaction with clinical placement and academic self-efficacy was directly proportional to students' achievement.
\end{abstract}

Keywords: Academic self-efficacy, achievement, clinical placement, nursing students, satisfaction.

\section{Introduction}

Nursing is essentially a practice-based profession therefore clinical placement is a vital and integral component in any nursing curricula [1]. European Union (EU) recommended that at least 50\% of the total hours from nursing studies have to be completed with clinical practicum experiences, and students must be supervised during these practice sessions [2]. Moreover [3] asserts that clinical placement is an interactive course work involving hands-on, direct care or service experience and evaluation of the student's skills.

Clinical placement should allow student nurses to combine intellectual, practical and communication skills, and develop competencies in the application of knowledge, skills, attitudes and values inherent in the nursing profession, however, not all practice settings are conducive to provide student nurses with positive clinical learning environments [4]. A study conducted by [5] indicated that educators must ensure that clinical placements are in an environment that is conducive to learning and promotes the personal and professional development of nursing students.

Clinical practice is an essential component in preparing nursing students to practice in the "real world" [6]. It is one of the most valuable and fertile available educational resources to institutions training nursing students. The experiences gained at the clinical settings assist students to grasp what the discipline of nursing is, provide them with opportunities to apply theories learned in the classroom to the real world of clinical nursing [7], and offer a desensitization through which students are introduced to the practices, expectations and real-life working environment of the nursing profession [8].

The main objectives of clinical nursing education are to combine the students' professional skills and knowledge needed for life-long learning, create self-confidence, ensure ability to make clinical decisions, be critical thinker, be independent, develop interpersonal skills, become involved into the protocols and expectations of the nursing profession and the health care system [9].

In fact the quality of the clinical learning environment (CLE) is considered an important factor for determining the quality of clinical student experience [10], and [11]. Overall, many studies demonstrated the importance of CLE in students' nursing learning competency [12]. Moreover, [13] indicated that when nursing students graduated without enough experience and with an insufficiency of practice it is originally contributed to inadequacy of the clinical learning environment.

Clinical learning environment has been defined by many as the place where the students practice and develop their clinical competences including the physical environment, teaching staff, nurses and other health professionals. It is important for the nursing students' learning, clinical skills, critical thinking, clinical decision making, self-monitoring skills and academic motivation during their clinical education [8]. It should provide 
Relationship between nursing students' clinical placement satisfaction, academic self-efficacy and ..

distinguished standards and safe patient care [14]. A recent study done [15] showed that higher satisfaction levels are attained when nursing students feel included and supported in the CLE during their learning journey.

Nursing students and health care staff as well appreciate clinical placements which provide students with quality learning experiences and meet the growing demands placed upon graduates [16]. The clinical placement environment influence students' experiences, career intentions, students' satisfaction with their placements and the degree to which their experiences are regarded as positive. In addition, clinical placement enhances students' confidence, organizational skills and preparedness for practice [17].

Self efficacy (SE) is defined as the belief in one's capabilities to achieve a goal or an outcome. It affects the choices made; it helps individuals to decide how much effort they will exert on a task, how long they will continue when experiencing difficulties, and how flexible they will emerge in deleterious situations [18]. It is considered a crucial factor in accounting for academic aspirations and academic achievement [19]. A study conducted by [20] revealed a reciprocal relationship between students' self-efficacy beliefs and academic achievement. Students with high or strong SE are more likely to challenge themselves with hard tasks, intrinsically motivated, improve quickly from setbacks, and by the end are likely to achieve their personal goals; on the other hand, students with little or poor SE, have little aspiration which may result in poor academic performances [21].

Self-efficacy is a key component for behaving independently in the nursing profession, and is essential for nursing students. Self-efficacy is vital to nurses' ability and performance in the clinical setting; nurses with high SE set appropriate goals, try different strategies, persevere to complete a task, and will make an easier transition from student to nursing professional [22]. In addition, if nursing students have high SE, they will perform well in nursing education [23].

Nurse educators should select clinical placements that offer a positive conducive learning environment to facilitate the achievement of clinical learning outcomes and look at the clinical experience through the students' eyes [4]. Considering the fact that learning in clinical placement had multiple facets, demonstrating a complex demanding nature, signifying that this area of learning is unpredictable and far beyond the control. Definitely exposure to positive clinical learning experience has an influence on nursing students' knowledge, skills, attitudes, and interest to continuing in nursing profession [24]. Many research findings suggested that nursing graduates are more likely to be employed in clinical settings in which they had positive experiences as students [17].

Study done by [25] emphasized that learning to be a nurse is a multidimensional process that demands time and work from two different perspectives: nursing practice in the field, and supervision and supportive relationship in learning settings. Hence, the students' clinical perspective on quality of clinical education contributes to the knowledge for the development of better educational experiences. In addition [26], and [27] highlighted the importance of assessing the clinical learning experiences while students are on placement.

Under current economic distress, there is a need to re-clarify and re-evaluate the potential roles of all parties involved in students' clinical learning and allow students to express their general satisfaction or dissatisfaction with clinical placement so that adequate preparation will be made to meet educational objectives [28]. Nursing students' satisfaction with clinical experiences is one important criterion used for the evaluation of clinical practice in nursing education as mentioned by [29].

Therefore, the researchers were interested to conduct this current study to investigate the relations between nursing students' clinical placement satisfaction, academic self-efficacy, and their achievement. The researchers were interested to conduct this current study among nursing students of Technical Institute rather than students' college.

\subsection{Significance of the study}

Nursing as a practice-based profession needs life-long learning, therefore clinical placement is a vital and integral because it provides the student the optimal opportunities to observe role models, practice by one's self which reflect upon what is seen, heard, sensed and done. So clinical placement evaluations from students' perspectives are very useful for better understanding of what constitutes quality clinical education and provide better educational experiences.

Despite the recognition of the importance of the complex context of the clinical setting, the impact of the type of clinical area on the achievement of student learning outcomes during clinical placement has not been assessed critically. Moreover, recent studies demonstrating that little is known about the impact of the clinical placement on students' competence, confidence and satisfaction and not many studies have focused on the satisfaction of students as related to clinical placements and investigate its relations with academic self-efficacy, and achievement among nursing students. 
Relationship between nursing students' clinical placement satisfaction, academic self-efficacy and ..

\subsection{Contribution of the study}

Findings of the current study might enhance the collaboration of educational institutions and clinical placement settings, and contributing to any potential reforms to optimize the learning activities and achievements within clinical settings and demonstrate more understanding of the relationship between study variables which lastly empower the teaching learning process of nursing students. Not only students learning will be achieved from clinical placement evaluation, but also the educational institution and the nursing services will gain benefits.

\section{Material and Methods}

The current study aims to investigate the relations between nursing students' clinical placement satisfaction, academic self-efficacy, and their achievement.

With this in mind, the following research questions were postulated:

1. What is the level of nursing students' clinical placement satisfaction?

2. What is the relationship among students' clinical placement satisfaction, academic self-efficacy and achievement?

3. What is the relationship among students' clinical placement satisfaction, gender, and achievement?

4. What is the relationship among students' academic self-efficacy, gender, and achievement?

\subsection{Design}

Descriptive correlational longitudinal panel research design was utilized in this study to describe the relationship among variables rather than to infer cause-and-effect relationships. Longitudinal panel designs involve data collection from the same subjects at more than one point in time over an extended period. Longitudinal designs are appropriate for studying the dynamics of a phenomenon over time. Longitudinal studies are typically expensive, time-consuming, and subject to the risk of attrition (loss of participants over time), but can produce extremely valuable information [30].

\subsection{Setting}

The current study was conducted at Technical Nursing Institute affiliated to Cairo University, where clinical training was conducted in a variety of clinical settings affiliated to Cairo University and Ministry of Health during the academic years 2014-2015 and 2015-2016.

Students at the first year (first and second term) were rotated through different clinical placements to fulfill the aim of providing basic nursing care for adult patients with different medical and surgical problems. On the other hand, students in second year were prepared to provide nursing care for children and women in childbearing and childrearing times in the first semester. While at the second semester, the students were concerned with providing nursing care to healthy and ill individuals and families in the community and managing patients with different psychiatric problems at out and inpatient psychiatric hospitals.

\subsection{Sample:}

The sample of the current study was nursing students affiliated to Technical Nursing Institute - Cairo University during two consecutive academic years; ninety sophomore nursing students at the academic year (2014-2015) as a first year students; eighty nursing students during the academic year (2015-2016) continued as second year students enrolled in different nursing courses and agreed to participate in this study. According to institute bylaws students were committed to study six nursing courses: during first year, students had two nursing courses namely; Fundamentals of Nursing, and Adult Nursing at first and second semester respectively. While during second year, students had four nursing courses; two parallel nursing courses/each semester at the same time, (Pediatrics Nursing and Obstetrics Nursing) and (Community Health Nursing and Psychiatric Nursing) at first and second semester respectively.

\subsection{Data collection tools:}

The researchers used three tools to gather data pertinent to fulfill the study aim as follows:

2.4.1. Personal data tool concerned with data related to students' personal data as gender, age, and year of study. Students' grades of all nursing courses were recorded by the researchers from the student's affairs department. 2.4.2. Students' satisfaction with clinical placement tool was developed by the researchers, based on reviewing literature and instruments related to the study scope [9], [31], and [32]. It is a self-report Arabic questionnaire designed to measure the nursing students' satisfaction with the clinical placement. It consists of 12 structured items covering the following areas: clinical training environment, students' support from health team members, achieving learning objectives, availability of learning opportunities, orientation to clinical setting, impact of placement on students' confidence level, value of clinical placement to students and students' readiness. Students' response for each items was rated on Likert scale from 1 to 5 where 1 indicated strongly disagree to 5 
Relationship between nursing students' clinical placement satisfaction, academic self-efficacy and ..

strongly agree. The scores of items were summed up and the total divided by the numbers of items given mean score. A higher mean score reflects higher levels of satisfactions. Four open ended questions were included at the end of the questionnaire to elicit students' responses regarding the positive and the negative aspects of clinical placement, how they assess themselves in the clinical setting, and their suggestions for clinical improvement. Researchers established validity of the questionnaire by jury of five experts in nursing field, and reliability through internal consistency by using Cornbach alpha; Coefficient alpha was established with a value of 0.85 .

2.4.3. College Academic Self-Efficacy Scale (CASES) was adopted; it was originally designed by [33]; the tool was translated into Arabic language and used by [34]. The content validity was checked. It consists of 32 items, students were asked to respond to a 5 point Likert type scale ranging from 1 or very little to 5 or a lot. CASES is scored by calculating mean scores, a higher mean scores reflects higher academic self- efficacy. The internal consistency reliability was measured by researchers and estimated to be 0.89 .

\subsection{Pilot study}

Pilot study was carried out on $10 \%$ of first year nursing students at Technical Nursing Institute who attends regularly classes and with acceptable attendance of clinical practice experience, to test clarity and feasibility of items to subjects and to test needed time for filling the tools. Some items required clarifications from researchers with no modification needed. Subjects who shared in the pilot study were not included in the study sample (researchers excluded students involved in pilot study from the study sample).

\subsection{Ethical considerations}

The study protocol was approved by the Research Ethics committee in Faculty of Nursing, Cairo University then approval from authoritative staff of Technical Nursing Institute - Cairo University was obtained to conduct the current study. Students were assured to express his/her opinion regarding their assigned clinical staff, opinions and attitudes toward their clinical placement while confidentiality and anonymity were applied through assigning a code number for each student instead of names to protect their privacy; students were informed that participation at the study was completely voluntarily and they had the right to withdraw at any time with no effect on their grades and evaluation. The students were assured that data are confidential and used only for research purposes.

\subsection{Procedure for data collection:}

After official permission, the researchers arranged time with coordinators of each nursing specialty to meet students and give full description for research aim and procedure and written informed consents were collected from students who agreed to participate in the study. The researchers started data collection through students' self-report after completion of their clinical experience at the end of first and second semester. The students were invited to fill out the data collection tools. All questions were answered and explanations were given accordingly. Then students' grades of nursing courses were obtained from authoritative personnel and recorded respectively.

\subsection{Statistical analysis:}

The data were analyzed using Statistical Package for Social Science software (SPSS version 18); for the descriptive results the following analysis: means, standard deviations, frequencies, percentages, and ranges were utilized. While for the inferential results, correlation and ANOVA test were tested. Significance level was counted when $\mathrm{P}$ value $\geq 0.05$. The internal consistency of all tools was conducted by Cronbach alpha.

\section{Results}

Results of the study are presented in two major parts; the first part is descriptive statistics that included the personal characteristics of the study sample, students' satisfaction with the clinical placement and the nursing students' academic self-efficacy, while the second one is inferential statistics that presents the relationships between the study variables; personal characteristics of the students, students' satisfaction with the clinical placement and the nursing students' academic self- efficacy. All respondents returned their questionnaires, indicating a $100 \%$ outcome.

Study sample' characteristics: As shown in Table (1) a total of 90 first year students and 80 of them as a second year students were approached to participate in the study with total 500 responses, they were assessed two times (one at the end of first semester and the other time at the end of second semester). The students' age ranged from $19-22$ years $(\mathrm{M} \pm \mathrm{SD}=19.8 \pm 0.86)$, and $75.8 \%$ were males.

Regarding students' satisfaction with clinical placement, the researchers found that $70.8 \%$ of the students were satisfied with their clinical placement. Fig. (1) depicted the items reported as more satisfied for the students were "prepared well for the required competencies in clinical placement, the health team members 
Relationship between nursing students' clinical placement satisfaction, academic self-efficacy and ..

expected the students' presence, and the placement enhanced the clinical skills" $(74.8 \%, 67.4 \%$, and $66.2 \%$ respectively), while fig. (2) presented the items which reported by the students as less satisfied were "the professional growth was supported during the clinical placement, students received learning support from their clinical supervisors during the clinical placement and as a result of the clinical experience, the students feel confident working in this setting" $(41.6 \%, 38 \%$, and $37 \%$ respectively).

Table (1): Frequency and percentage distribution of the study subjects' characteristics $(n=170)$.

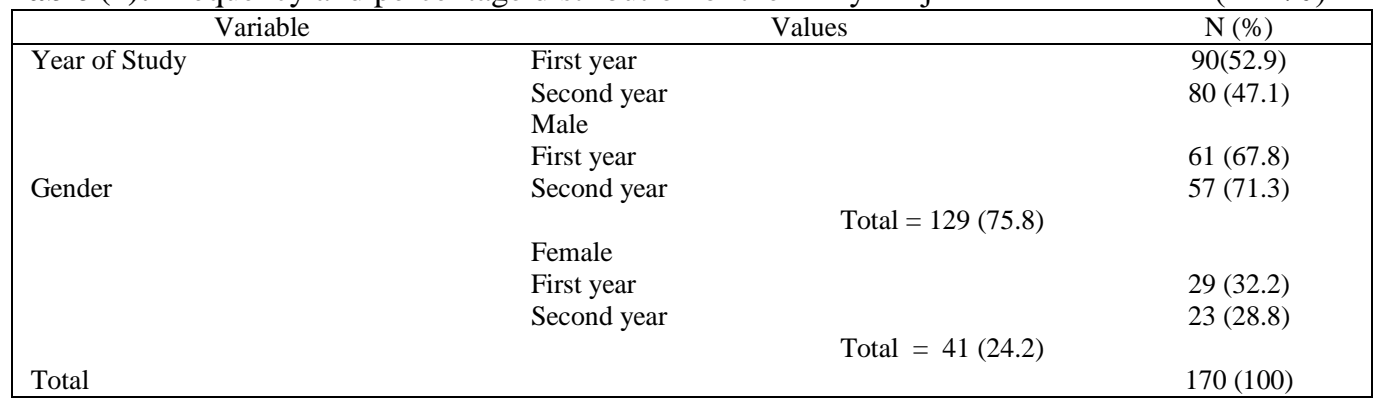

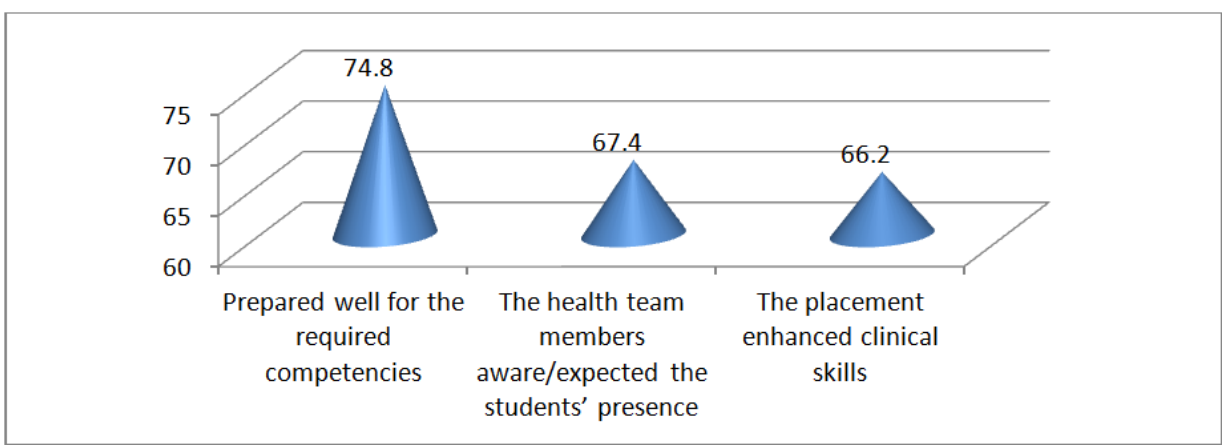

Figure (1): Overall highly satisfied items regarding students' satisfaction with their clinical placement $(n=500)$.

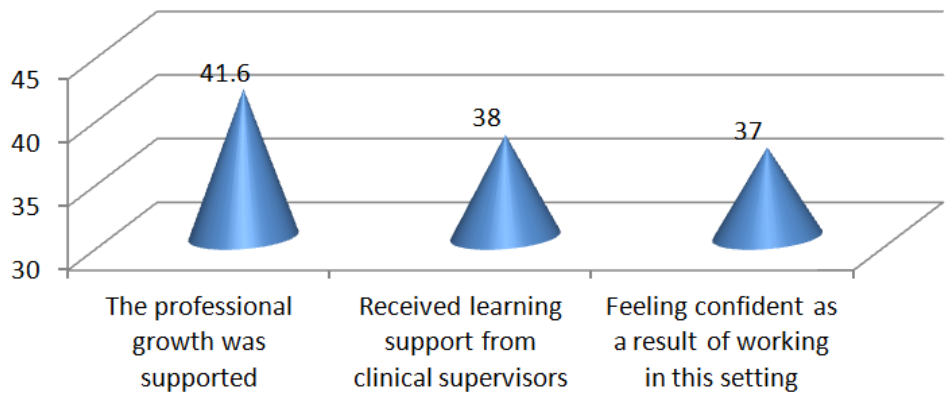

Figure (2): Overall highly unsatisfied items regarding students' satisfaction with their clinical placement $(n=500)$.

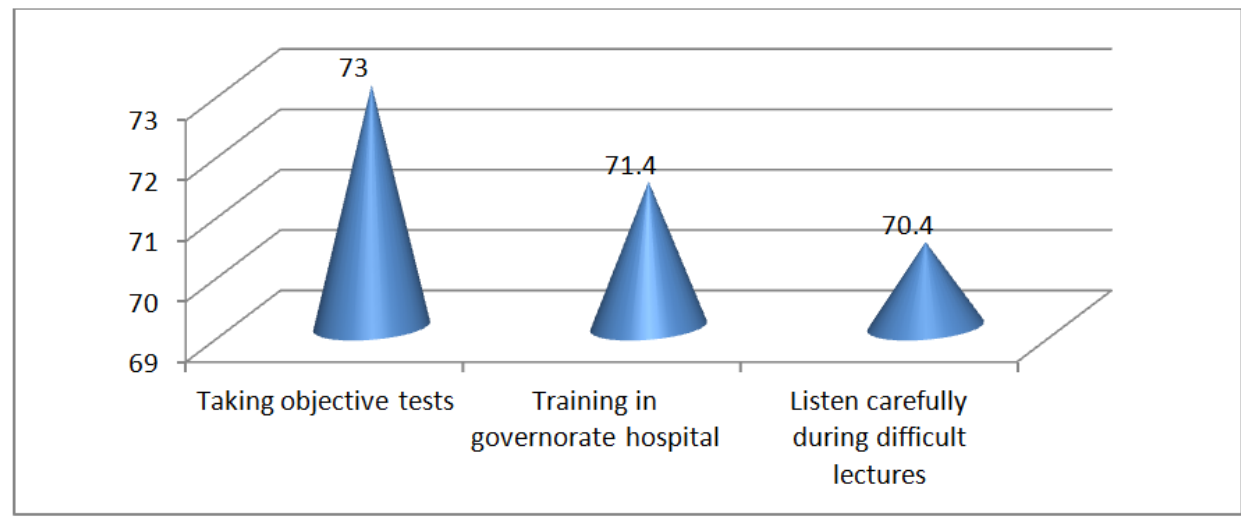

Figure (3): Items increasing nursing students' academic self-efficacy $(n=500)$. 


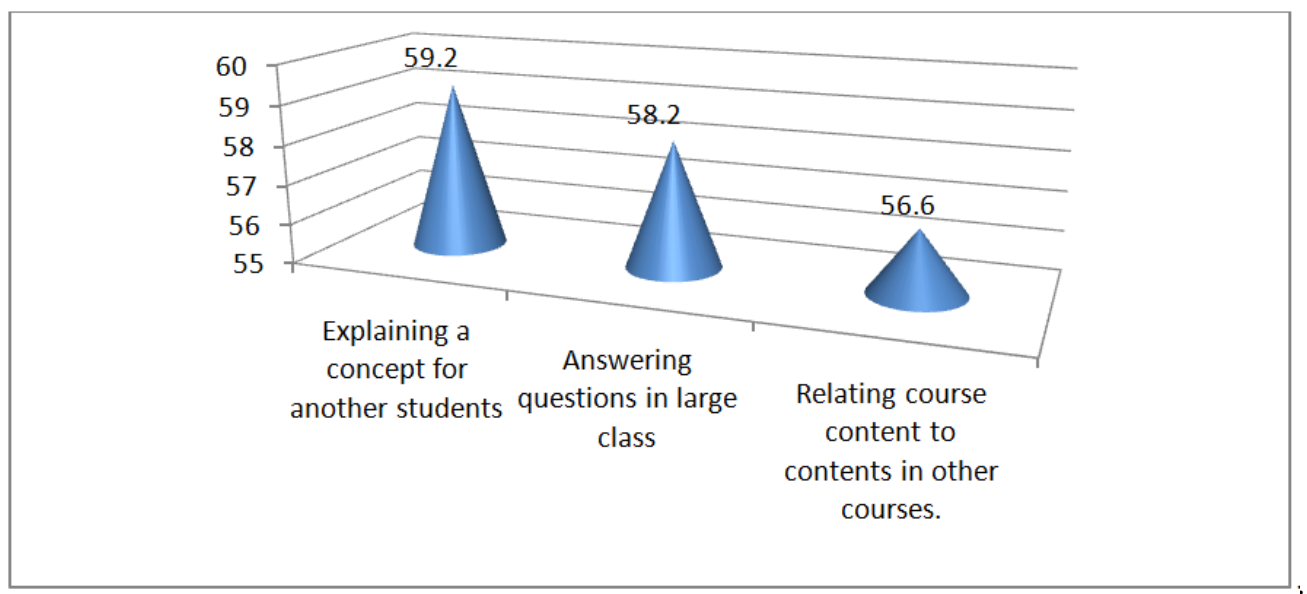

Figure (4): Items decreasing nursing students' academic self-efficacy $(n=500)$

Data revealed that $54.7 \%$ of the nursing students had higher academic self-efficacy. Fig. (3) illustrated the items reported by students which increase their academic self-efficacy during academic studying as "taking objective tests (MCQ, T \& F), training in governorate hospital, and listen carefully during difficult lectures" ( $73 \%, 71.4 \%$, and $70.4 \%$ respectively). While the students reported some items which affect their academic selfefficacy negatively in fig. (4) as "explaining a concept for another students, answering questions in large class, and relating course content to contents in other courses" (59.2\%, 58.2\%, and 56.6\% respectively).

Table (2) showed that students were more satisfied with clinical placement related to "Pediatric nursing, and Fundamental nursing" specialties where the mean scores were $3.83 \pm 0.38$, and $3.82 \pm 0.62$, respectively, while the less satisfied clinical placement were related to "Obstetrics nursing, and Psychiatric nursing" where the mean scores were $3.68 \pm 0.64$, and $3.69 \pm 0.52$ respectively. However there was no significant correlation between students' satisfaction with clinical placement and different nursing specialty courses.

Table (2): Correlation between students' satisfaction with clinical placement and clinical setting related to nursing specialty courses $(n=170)$.

\begin{tabular}{|c|c|c|c|}
\hline \multirow[t]{2}{*}{ Nursing specialty courses } & \multicolumn{3}{|c|}{ Students' satisfaction with clinical placement } \\
\hline & Mean \pm SD & F-value & p-value \\
\hline Fundamental nursing & $3.82 \pm 0.62$ & & \\
\hline Adult nursing & $3.73 \pm 0.67$ & & \\
\hline Obstetric nursing & $3.68 \pm 0.64$ & & \\
\hline Community health nursing & $3.70 \pm 0.55$ & & \\
\hline
\end{tabular}

Students' number is not mutually exclusive

*Significant $\mathrm{P}$ value $\geq 0.05$

Table (3) revealed highly statistical significant correlation between students' self-efficacy and clinical settings related to different nursing specialties $(\mathrm{F}=5.382$ at $\mathrm{p} .0001)$. Students reported more academic self-efficacy with "Fundamental nursing, Obstetric nursing, and Psychiatry nursing" where their means scores were 3.69, 3.59 and 3.56 respectively.

Table (3): Correlation between students' academic self-efficacy and clinical setting related to nursing specialty courses $(n=170)$.

\begin{tabular}{|llc|}
\hline Clinical setting related to nursing specialty & Students' academic self-efficacy \\
courses & Mean \pm SD & F-value \\
\hline Fundamental nursing & $3.69 \pm 0.59$ & 5.382 \\
Adult nursing & $3.50 \pm 0.27$ & $.0001^{* *}$ \\
Pediatric nursing & $3.36 \pm 0.31$ & \\
Obstetric nursing & $3.59 \pm 0.67$ & \\
Community nursing & $3.43 \pm 0.34$ \\
Psychiatry nursing & $3.56 \pm 0.48$ \\
Total & $3.52 \pm 0.47$ & \\
\hline
\end{tabular}

$*$ Significant $\mathrm{P}$ value $\geq 0.05$ 
Relationship between nursing students' clinical placement satisfaction, academic self-efficacy and ..

Table (4) demonstrated correlations of some personal variables and students' achievement in nursing courses and overall satisfactions and efficiencies. A highly statistical significant negative correlation was detected between students' ages and their levels of academic self-efficacy $(\mathrm{F}=4.263$ at $\mathrm{p}=.005)$. A highly statistically significant positive correlation was detected between students gender and their levels of satisfactions with clinical placement $(\mathrm{F}=5.291$, at $\mathrm{p}=.022)$, however female students were more satisfied than male students. A highly statistical significant positive correlations were found between students' grades in nursing courses and their levels of satisfactions with clinical placement and academic self-efficacy $(\mathrm{F}=4.230$ at $\mathrm{p}=.001$, and $\mathrm{F}=10.989$ at $\mathrm{p}=.000$ respectively). As shown in Table (5) there was a statistical significant correlation among students' achievement of some nursing specialty courses as Pediatric nursing, Community nursing, and Psychiatry nursing and satisfaction with clinical placement and academic self-efficacy, while other nursing specialty courses didn't prove to be significantly correlated. However, satisfaction with clinical placement and academic self-efficacy was directly proportional to students' achievement.

Table (4): Correlation between selected personal variables and students' satisfaction with clinical placement and academic self-efficacy $(\mathrm{n}=170)$

\begin{tabular}{|c|c|c|c|c|c|c|}
\hline \multirow[t]{2}{*}{ Personal variables } & \multicolumn{2}{|c|}{ Age } & \multicolumn{2}{|c|}{ Gender } & \multicolumn{2}{|c|}{$\begin{array}{l}\text { Achievement in nursing } \\
\text { course }\end{array}$} \\
\hline & F-value & p-value & F-value & p-value & F-value & p-value \\
\hline Satisfaction with clinical placement & .304 & .823 & 5.291 & $.022 *$ & 4.230 & $.001 * *$ \\
\hline Type of correlation & \multicolumn{2}{|c|}{ Negative } & \multicolumn{2}{|c|}{ Positive } & \multicolumn{2}{|c|}{ Positive } \\
\hline
\end{tabular}

* Significant $\mathrm{P}$ value $\geq 0.05$

Table (5): Correlation among students' achievement, satisfaction with clinical placement and their academic self- efficacy $(\mathrm{n}=170)$.

\begin{tabular}{|c|c|c|c|c|c|c|c|}
\hline \multirow[t]{2}{*}{ Nursing courses } & \multirow{2}{*}{$\begin{array}{l}\text { Achievement } \\
\text { Level }\end{array}$} & \multicolumn{3}{|c|}{ Satisfaction with clinical placement } & \multicolumn{3}{|c|}{ Academic self-efficacy } \\
\hline & & Mean $\pm \mathrm{SD}$ & F value & $\mathrm{P}$ value & Mean \pm SD & F value & $P$ value \\
\hline \multirow{3}{*}{$\begin{array}{l}\text { Fundamentals of } \\
\text { nursing }\end{array}$} & Pass & $3.76 \pm 0.58$ & & & $3.48 \pm 0.47$ & & \\
\hline & V. good & $3.95 \pm 0.62$ & & & $3.71 \pm 0.60$ & & \\
\hline & Excellent & $3.92 \pm 0.59$ & & & $3.95 \pm 0.57$ & & \\
\hline \multirow[t]{3}{*}{ Adult nursing } & Fail & $3.43 \pm 0.85$ & & & $3.35 \pm 0.40$ & & \\
\hline & V. good & $3.89 \pm 0.66$ & & & $3.61 \pm 0.23$ & & \\
\hline & Excellent & $3.47 \pm 0.89$ & & & $3.33 \pm 0.26$ & & \\
\hline \multirow[t]{3}{*}{ Pediatric nursing } & Fail & $3.56 \pm 0.17$ & & & $3.10 \pm 0.23$ & & \\
\hline & Pass & $3.57 \pm 0.25$ & & & $3.07 \pm 0.23$ & & \\
\hline & Good & $3.83 \pm 0.47$ & 6.272 & $.0001 * *$ & $3.40 \pm 0.19$ & 12.987 & $.0001^{*}$ \\
\hline \multirow{3}{*}{ Obstetric nursing } & Good & $3.69 \pm 0.54$ & .644 & .633 & $3.59 \pm 0.53$ & 1.181 & .326 \\
\hline & V. good & $3.78 \pm 0.65$ & & & $3.51 \pm 0.78$ & & \\
\hline & Excellent & $3.67 \pm 0.72$ & & & $3.82 \pm 0.65$ & & \\
\hline \multirow[t]{5}{*}{ Community nursing } & Fail & $3.69 \pm 0.56$ & & & $3.31 \pm 0.28$ & & \\
\hline & Pass & $3.67 \pm 0.59$ & & & $3.39 \pm 0.31$ & & \\
\hline & Good & $3.48 \pm 0.63$ & 3.892 & $.006 * *$ & $3.24 \pm 0.39$ & 6.377 & $.0001^{*}$ \\
\hline & V. good & $3.54 \pm 0.38$ & & & $3.36 \pm 0.26$ & & \\
\hline & Excellent & $4.14 \pm 0.44$ & & & $3.77 \pm 0.29$ & & \\
\hline \multirow[t]{4}{*}{ Psychiatry nursing } & Fail & $3.18 \pm 0.38$ & & & $2.93 \pm 0.28$ & & \\
\hline & Pass & $3.54 \pm 0.29$ & & & $3.35 \pm 0.20$ & & \\
\hline & Good & $3.69 \pm 0.50$ & 5.160 & $.001 * *$ & $3.59 \pm 0.53$ & 12.495 & $\begin{array}{c}.0001^{*} \\
*\end{array}$ \\
\hline & V. good & $3.95 \pm 0.46$ & & & $3.70 \pm 0.41$ & & \\
\hline
\end{tabular}

*Significant $\mathrm{P}$ value $\geq 0.05$

\section{Discussion}

The study sample's age ranged between 19-22 years, about three fourth of them were males, this high percent of male students is not unique to Egyptian nursing students but also other studies reported global increase in the number of males entering the nursing profession as reported by [35], and [36]. Regarding their grades in the nursing courses, half of the sample grades varied from good to very good which reflected normal distribution.

Overall, more than two thirds of students were satisfied about their learning experiences from the clinical placement. The items reported as more satisfied were their feeling of well preparation for the required 
Relationship between nursing students' clinical placement satisfaction, academic self-efficacy and ..

competencies in clinical placement, and the health team members aware/expected the students' presence. This may be related to the inclusion of orientation period (two weeks) in the nursing course syllabus prior to students clinical placement where all issues related to clinical placement such as course intended learning outcomes, procedures to be acquired, time for training, responsible personnel, duties, plan of clinical areas, evaluation items, and also availability of clinical areas that facilitate providing nursing care and applying the theory in practice.

The study' results are supported with [37] and [38] who reported students satisfaction with placement mainly because they met their placement objectives, enjoyed their time and worked as a team who are willing and available staff that assisted them in learning. Studies conducted by [39] and [17] indicated that all students, regardless of location, rated higher satisfaction with their clinical experiences. In the same line [40] added that students indicated that the placement was a pleasant learning experience they had adequate knowledge. The majority of students perceived their clinical placement as rich in learning experiences as they having been exposed to a wide range of clinical experiences. While another study done by [41] indicated that students perceived placement experience as challenging, unpredictable and stressful.

Students pointed out to the most unsatisfied items with clinical placement as "the professional growth was supported during the clinical placement, students received learning support from their clinical supervisors during the clinical placement and as a result of the clinical experience, and students feel confident working in this setting". This is might be related to the short rotation of the clinical placement as it usually ranged from 2-3 weeks in each clinical setting. This result was in the same direction of other studies [42], and [24] reported that students' are less satisfied in response to their clinical placement mainly when clinical rotation is too short as students could not get familiar with the unit, and get less advantages of learning.

In spite of willingness of some staff nurses to and interested in helping students in clinical placement, they are not aware of the skills and strategies necessary in clinical education and, are not prepared for their role to act as an instructor, therefore, shortage and lack of well experienced staff could affect students' satisfaction levels with clinical placement. Similarly, [24] reported that nursing staff are always busy with their duties and they are unable to have both education and service role; in addition, the instructors have a more evaluative role than a teaching role which causes a stress more than support at the clinical area.

Students were asked to respond to four open ended questions to have further input explaining how they felt about their experiences with clinical placement. Open ended questions were directed toward eliciting responses from the students regarding the positive and the negative aspects of clinical placement, how they assess themselves in the clinical setting, and their suggestions for clinical improvement. Some of the significant remarks from the students were: "personal relation with the clinical instructor has a significant impact on students' satisfaction with clinical placement"; "adequate orientation period provide students confidence and familiarity with the clinical placement"; "varieties of clinical settings and clinical approaches help us in gaining distinguished experiences"; "training in governmental hospital gives us the opportunity to practice with the most common health problems"; "students' awareness of the desired outcomes"; "helpful contribution received from some nurses and doctors"; and "using standardized evaluation sheets".

The negative aspects of clinical placement contributing for dissatisfaction with the clinical placement as expressed by students were: "some clinical instructors are subjective"; "some clinical instructors" abilities and expertise are questionable"; "lack of integration of knowledge and practice"; "given comments by instructors in unacceptable way"; "most of the instructors emphasized on negative rather positive aspects during evaluation"; "supervision sessions are scattered and unplanned frequently"; "the clinical placement for each clinical rotation is too short, makes us unfamiliar with the clinical setting"; "we were not allowed to practice many nursing procedures" and "lack of students awareness of formative evaluation". Regarding students' selfassessment, the majority of the students over estimated themselves, they agreed that "they are actively participated in clinical practice"; "acquired knowledge and skills from their participation in the training process"; and achieved the expected clinical learning outcomes".

Students suggested recommendation regarding the duration of the clinical placement and the role of the clinical instructors as follows: "increase period of each clinical rotation for maximizing efficiency of necessary skills"; "the instructor should ensure that the student has practiced in all clinical procedures more than once before coming to the clinical area and before evaluation"; "give incentive and rewards based on academic performance in clinic areas"; and "constructive feedback should be given to students"; and "the instructor should emphasize on the teaching rather than the evaluation". Similar comments are documented by other studies [43], and [27].

A study entitled "Nursing student's perception of anxiety-producing situations in the clinical setting" by [41] viewed observation and evaluation of students as necessary aspects of the clinical learning environment, should be performed in a supportive, nonthreatening manner and be used for formative guidance, not just summative evaluation. Therefore, [27] emphasized the importance of competent and skilled clinical facilitators 
Relationship between nursing students' clinical placement satisfaction, academic self-efficacy and ..

who know how and what to teach; provide immediate help and support, and guide students through difficult tasks at any time they instead of waiting for the opportunity to criticize.

Less than half of the nursing students had lower academic self-efficacy; however, this frustrating result was expected as the students affiliated to technical nursing institute were deprived from students' services and activities rendered to other students affiliated to all faculties of the university. Participants of this study were suffering from many problems such as failure to allocate a separate building for them and the current location lacks the existence of essential educational constituents (skills labs, computer labs, language labs, and halls to change clothes and places to eat and enough toilets to accommodate the number of students... etc). Students were also suffered from a lack of Department of Youth Welfare in the institute to satisfy their needs for different Youth Welfare activities like the rest of the students' faculties of the university.

However, little is known about self-efficacy of nursing students affiliated to Technical Nursing Institute; studies in this issue were concerned with nursing students affiliated to nursing colleges. Research conducted by [44] reported in their study that about $65 \%$ to $72 \%$ of the students had very high or high selfefficacy. Also, [23] reported that most of the nursing students in their study had a high level of self-efficacy. A study on associate degree nursing students done by [45] found that a total of $82 \%$ of these students reported high self-esteem, and 77\% indicated high self-efficacy. While other study entitled "Parenting Styles, Identity Styles and Academic Adjustment as Predictors of Academic Self-Efficacy among Hashemite University Students" found that academic self-efficacy among Hashemite University' Students was average [34].

Taking objective tests (MCQ \& T/F), training in governorate hospital, listen carefully during difficult lectures, writing high quality term papers, taking well organized notes during lectures, attending class regularly, and making good use of library were recognized by high percentages of students as items for students' positive academic self-efficacy. These items were recognized as the main elements which help in achieving successful educational process, potentiate utilization of students' skills as problem solving, and critical thinking, encourage active rather than passive learning through using internet and recent literature in developing assignments which enhance confidence and independency among students.

Students expressed more satisfactions with clinical rotations of Pediatrics nursing course this might be mainly related to the uniqueness of skills, and experiences related to this specialty in addition to dynamicity and emergency of situations' that trigger problem solving ability, critical thinking and provide challenging opportunities for them. This result is in accordance with [39], [46] and [32] who indicated that not all practice settings are able to provide students with a positive learning environment. However, students reported less satisfaction with clinical rotation of Obstetric, and Psychiatry nursing courses this result could be explained in form of students' sensitivity to those specialties which did not appeal to some students especially male ones. This result isn't in the same line with others.

Students also reported more satisfactions and academic self-efficacy of clinical placements in Fundamental of nursing course. This could be explained as the students are motivated and showed interest during their initial step on their career, so they tend to work hard, face challenges and achieved well. This result is contradicted with other studies [1], [47], and [48] who reported that students perceived placement experience as challenging, unpredictable and stressful particularly in the first clinical placement. Also, [49] found that $83.3 \%$ of the students had little satisfaction as to the situation of educational environment, $47.2 \%$ about situation of clinical environment.

Data analysis revealed positive correlations between students' satisfactions and academic efficiencies and their last semester nursing course achievements. This could be explained in form of students' levels of performance, and achieved activities can affect their viewpoints about their educational achievements which in turn create motivation and promote more satisfactory levels. The study finding was in accordance with study carried out by [50] who found that the general self-efficacy level is a predictor for medical undergraduates' academic achievement.

On the same line, [20] reported that the effect of past academic performance on self-efficacy beliefs was larger than the effect of self-efficacy beliefs on academic achievement. A recent study conducted by [51] at Kant Kaw Education Center in Myanmar reported a positive relationship between the levels of students' satisfaction and their achievement. However, the current study didn't prove significant correlations between students' achievements scores' and their academic efficacies and satisfactions.

Statistical significant negative correlation was detected between students' ages and their levels of academic efficiencies. This might be related to the students' overload and involvement in more than one nursing course at the same semester at second year which lead to physical, mental and psychological exhaustions and minimize their capabilities. The present study revealed statistical significant differences regarding clinical placement satisfactions and gender, where female students were more satisfied than male students. This was ought to the mutual association of female gender role and providing care to others rather than male students who are incapable of providing intimate and sensitive care in certain clinical place as with females and lack of encouragement from some doctors and nurses which in turns lead to lack of satisfactions among male students. 
In [52] study, self-efficacy was found to be significantly correlated to student's academic performance $(\mathrm{r}=.25 ; \mathrm{p}<\% 1)$, but a significant relation was not found between academic achievement and age, self-regulation, and achievement goals. Also, [23] reported no statistically significant difference in self-efficacy score before and after skills training with regard to students' age, gender, and level of education. They related their findings to environmental, cognitive and behavioral interaction processes which affect self-efficacy; therefore, selfefficacy could be related to the individual's life experiences rather than his or her age.

\section{Conclusion}

The study gets the attention to the many positive as well as negative aspects of the clinical experience of the nursing students at the technical nursing institute. Under current economic distress, there is a need to reclarify the potential roles of all parties involved in students' clinical learning so that adequate preparation should be made to meet educational objectives. A conducive and supportive environment can be created when aims of the service and educational sectors are merged in a climate that encourages collaborative learning, trust and mutual respect. Moreover, opportunities should be provided for students to reflect and verbalize their feelings about their clinical experiences, positive or negative. Nursing students' satisfaction level could be used as an important contributing factor towards the development and/or reforms of clinical learning environments in order to satisfy the needs and expectations of students.

The current study also, offers worthwhile contributions to self-efficacy research. Specifically, it highlights the relationship between self-efficacy and academic achievement; the study demonstrated a reciprocal relationship between self-efficacy and academic. Therefore, educators should focus on interventions that target both self-efficacy and past academic performance using past academic performance to foster increased selfefficacy.

\section{Limitation}

The findings of this study are limited to the students' perspective and based on data from one nursing institute, therefore, the results might be neither representative nor generalized. Some limitations should be noted when drawing firm inferences from the findings of this study due to the relatively short periods of time spent in specific ward environments, specifically from two to three days per week during a period of seven to eight weeks as "short clinical rotations". These may not provide sufficient time to build mutual understanding and familiarity within the specific CLE. However students' satisfaction could not be considered as the only measurement to assess the CLE's impact on students' learning and development.

\section{Implications and recommendations}

1. Students' assessment and evaluation as essential aspects of the clinical learning environment should be performed in a supportive, nonthreatening manner and be used for formative guidance, not just summative evaluation

2. Continues development of clinical instructors' skills to be more competent and skillful and to know how and what to teach should be a priority.

3. Counseling sessions are needed to help students to verbalize their feelings about their clinical experiences.

4. Role of academic guidance must be enhanced to follow students during guiding sessions and detected any problems facing students.

5. Flexible and multiple learning strategies, such as workbooks, online learning, and simulation laboratories, have been proposed to meet the needs of students as learning tools.

6. Further investigation of satisfaction of clinical teachers regarding the efficiency of students in the hospital environment clinical training may be required.

7. Further research study regarding perceptions of the clinical learning environment from clinicians, clinical teachers, as well as patients, will provide a broader spectrum to complete the picture.

\section{Acknowledgement}

Grateful thanks to the students' who trust us and participate in this work for their valuable efforts and time. The authors acknowledge there was no external financial support for this study. We, also thank the anonymous reviewers for their constructive comments that helped strengthen the article.

\section{References}

[1]. Henderson, A. Cooke, M. Creedy, K and Walker, R. (2012). Nursing students' perceptions of learning in practice environments: A review. Nurse Education Today, 32 (3), 2012, 299-302.

[2]. Jokelainen, M. Turunen, H. Tossavainen, K. Jamookeeah, D. and Coco, K. (2011). This systematic review described mentoring of nursing students in clinical placements. Journal of Clinical Nursing; 2011, 20 (19-20), 2854-67.

[3]. Sugden, N. (2007). Meeting the challenge of expanding clinical nursing opportunities. In: Statewide Clinical Placement Summit. Wisconsin, USA. 
Relationship between nursing students' clinical placement satisfaction, academic self-efficacy and ..

[4]. Chan, D. (2004). The relationship between student learning outcomes from their clinical placement and their perceptions of the social climate of the clinical learning environment. Contempt nursing. 2004, 17(1-2), 149-58.

[5]. Hartigan-Rogers, J. Cobbett, S. Amirault, M and Muise-Davis, M. (2007). Nursing graduates' perceptions of their undergraduate clinical placement. International Journal of Nursing Education Scholarship, 4(1) 2007.

[6]. Egan, T. and Jaye, C. (2009). Communities of clinical practice: the social organization of clinical learning. International Health, $2009,13,107-125$.

[7]. Elcigil, A. and Sarı, H. (2007). Determining problems experienced by student nurses in their work with clinical educators in Turkey. Nurse Education Today; 2007, 27: 491-498.

[8]. Papastavrou, E. Lambrinou, E. Tsangari, H. Saarikoski, M. and Leino-Kilpi, H. (2010). Student nurses experience of learning in the clinical environment. Nurse Education in Practice; 2010, 10: 176-182.

[9]. Papp, I. Markkanen, M. and Von Bonsdorff, M. (2003). Clinical environment as a learning environment: student nurses' perceptions concerning clinical learning experiences. Nurse Education Today,(2003),23: 262-268.

[10]. Perli, S. and Brugnolli, A. (2009). Italian nursing students' perception of their clinical learning environment as measured with the CLEI tool. Nurse Education Today, 2009, 29, 886-890.

[11]. D’Souza, M. Karkaba, S. Parahoo, K. and Venkatesaperumal, R. (2015). Perception of and satisfaction with the clinical learning environment among nursing students. Nurse Education Today; 2015, 35 (6), 833-840.

[12]. Sharghi, N. Alami, A. Khosravan, S. Mansoorian, M. and Ekrami, A. (2015). Academic training and clinical placement problems to achieve nursing competency. Journal of Advances in Medical Education and Professionalism; 2015 Jan; 3(1): 15-20.

[13]. Aktas, Y. and Karabulut, N. (2016). A survey on Turkish nursing students 'perception of clinical learning environment and its association with academic motivation and clinical decision making. Nurse Education Today; 2016, 36, 124-128.

[14]. Safadi, R. Jaradeh M. Bandak A. and Froelicher, E. (2010). Competence assessment of nursing graduates of Jordanian universities. Nursing and Health Sciences; 2010, 12(2):147-54.

[15]. Walker, S. Rossi, D. Anastasi, J. Gray-Ganter, G. and Tennent, R. (2016). Indicators of undergraduate nursing students' satisfaction with their learning journey: An integrative review. Nurse Education Today; 2016, 43(4), 40-48.

[16]. Clare, J. White, J. Edwards, H. and Van Loon, A. (2002). Curriculum, clinical education, recruitment, transition and retention in nursing. AUTC Phase One Final Report, Flinders University, Adelaide, Australia.

[17]. Edwards, H. Smith, S. Courtney, M. Finlayson, K. and Chapman, H. (2004). Impact of clinical placement location on nursing students' competence and preparedness for practice. Nurse Education Today; 2004, 24(4):248-255

[18]. Bandura, A. (2001). Social cognitive theory: An agentive perspective. Annual Review of Psychology, 2001, 52(1), 1-26.

[19]. Komarraju, M. and Nadler, D. (2013). Self-efficacy and academic achievement: Why do implicit beliefs, goals, and effort regulation matter? Learning and Individual Differences, 2013, 25, 67-72.

[20]. Hwang, M. Choi, H. Lee, A., Culver, J. and Hutchison, B. (2016). The relationship between self-efficacy and academic achievement: A 5-year panel analysis. The Asia-Pacific Education Researcher; 2016, 25(I), 89-98.

[21]. Margolis, H. and McCabe, P. (2004). Improving self-efficacy and motivation: What to do, what to say. Intervention in School \& Clinic; 2004, 41(4), 218-227.

[22]. Dearnley, C. and Meddings, F. (2007). Student self-assessment and its impact on learning- a pilot study. Nurse Education Today; 2007; 27(4):333-40

[23]. Karabacak Ü, Serbest, Ş., KanÖntürk, Z., EtiAslan, F., and Olgun, N. (2013). Relationship between student nurses' self-efficacy and psychomotor skills competence. International Journal of Nursing Practice; 2013, 19: 124-130.

[24]. Levett-Jones, T. Fahy, K. Parsons, K. and Mitchell, A. (2006). Enhancing nursing students' clinical placement experiences: a quality improvement project. Contemporary Nurse; 2006, 23:58-71.

[25]. Serrano-Gallardo, P. Martínez-Marcos, M. Espejo-Matorrales, F. Arakawa, T. Magnabosco, G. and Pinto, I. (2016). Factors associated to clinical learning in nursing students in primary health care: an analytical cross-sectional study. Revista LatinoAmericana de Enfermagem, 24, e2803.2016, 09.

[26]. Lee, Y. Barnard, A. and Owen, C. (2011). Initial evaluation of rural programs at the Australian National University: Understanding the effects of rural programs on intentions for rural and remote medical practice. Rural Remote Health; 2011, 11 (2):1602.

[27]. Abouelfettoh, A., and Al Mumtin, S. (2015). Nursing students' satisfaction with their clinical placement. Journal of Scientific Research \& Reports, 2015; 4(6): 490-500.

[28]. Papastavrou, E. Dimitriadou, M. Tsangari, H. and Andreou, C. (2016). Nursing students' satisfaction of the clinical learning environment: a research study. BMC Nursing 2016, 15:44.

[29]. Lee, C. Y. White, B. and Hong, Y. M. (2009). Comparison of the clinical practice satisfaction of nursing students in Korea and the USA. Nursing \& Health Sciences; 2009, 11 (1), 10-16.

[30]. Polit, D. and Beck, C. (2010). Nursing research. Principles and methods. $7^{\text {th }}$ ed., Lippincott. Page 166.

[31]. Penman, J. and Oliver, M. (2004). Meeting the challenges of assessing clinical placement venues in a Bachelor of Nursing program. Journal of University Teaching \& Learning Practice, 1(2), 2004.

[32]. Henriksen, N. Normann, H. and Skaalvik, M. (2012). Development and Testing of the Norwegian Version of the Clinical Learning Environment, Supervision and Nurse Teacher (CLES+T) Evaluation Scale. International Journal of Nursing Education Scholarship; 2012, 9 (1).

[33]. Owen, S. and Froman, R. (1998). Development of a college academic self-efficacy scale. Paper presented at the 1998 annual meeting of the National Council on Measurement in Education.

[34]. AL-Baddareen, G. and Ghaith, S. (2013). Parenting styles, identity styles and academic adjustment as predictors of academic selfefficacy among Hashemite university students. Jordanian Journal of Educational Sciences, Amman; 2013, 9 (1), 65 -87.

[35]. Ierardi, J. Fitzgerald, D. and Holland, D. (2015). Exploring male students' educational experiences in an associate degree nursing program. Journal of Nursing Education; 2015, 49(4):215-8.

[36]. Eswi, A. and El Sayed, Y. (2011). The experience of Egyptian male student nurses during attending mate366rnity nursing clinical course. Nurse Education in Practice; 2011, 11(2), 93- 98.

[37]. Mantzoukas, S and Jasper, M. (2004). Reflective practice and daily ward reality: a covert power game. Journal of Clinical Nursing; 2004, 13(8):925-933.

[38]. Newton, J. Jolly, B. Ockerby, C. and Cross, W. (2010). Clinical learning inventory: Factor analysis. Journal of Advanced Nursing; 2010, 66(6):1371-1381.

[39]. Framtz, J. and Rhoda, A. (2007). Assessing Clinical Placements in a B.Sc. Physiotherapy Program. The Internet Journal of Allied Health Sciences and Practice; 2007, 5(3).

[40]. Kyei, K. Bruce, A. Antwi W. and David, N. (2014). Impact of clinical placement on radiography students in Ghana. International Journal of Medical Research \& Health Sciences; 2014, 3(4). 819-824. 
[41]. Kleehammer, K. Hart, A. and Fogel, K. (1990). Nursing student's perception of anxiety-producing situations in the clinical setting. Journal of Nursing Education; 1990, 29 (4):183-87.

[42]. Adams, V. (2002). Consistent clinical assignment for nursing students compared to multiple placements. Journal of Nursing Education, 2002; 41 (2):80-82.

[43]. Al-Kandari, F. Vidal, V. and Thomas, D. (2009). Assessing clinical learning outcomes: A descriptive study of nursing students in Kuwait. Nursing and Health Sciences.2009, 11(3)252-262.

[44]. Rezayat, F. and Nayeri, N. (2013). Self-Efficacy after Life Skills Training: A Case-Control Study. Nursing and Midwifery Studies; December 2013, 2(4): 83-88

[45]. Peterson-Graziose, V. Bryer, J. and Nikolaidou, M. (2013). Self-esteem and self-efficacy as predictors of attrition in associate degree nursing students. Journal of Nursing Education. 2013; 52(6):351-4.

[46]. Warnea, T. Johansson, B. Papastavrouc, E. Tichelaard, E. Tomiettoe, M. Bosschef, V. VizcayaMorenog, M. and Saarikoskih, M. (2010). An exploration of the clinical learning experience of nursing students in nine European countries. Nurse Education Today; 2010, 8 (30): 809-815.

[47]. Anthony, M.andYastik, J. (2012). Nursing student's experiences with incivility in clinical education. Journal of Nursing Education; 2012, 50 (3), 140-144.

[48]. Kajander-Unkuri, S. Meretoja, R. Katajisto, J. Saarikoski, L. Suhonen, R. and Leino-Kilpi, H. (2014). Self-assessed level of competence of graduating nursing students and factors related to it. Nurse Education Today; 2014, 34, 795-801.

[49]. Hakim A. (2014). Nursing students' satisfaction about their field of study. Journal of Advances in Medical Education Professionalism; Apr. 2014,2(2):82-7.

[50]. Long, B. (2008). Medical undergraduates effect of general self-efficacy on study result. China. Journal of Health Psychology; 2008, 16(5):483-484.

[51]. Aung, J. and Ye, Y. (2016). The relationship between the levels of students' satisfaction and their achievement at Kant Kaw education center in Myanmar. Retrieved from www.assumptionjournal.au.edu/index.php/Scholar/article/download/2184/1533

[52]. Ergul, H. (2004). Relationship between students' characteristics and academic achievement in distance education and application to students of Anadolu University in Turkish. Online Journal of Distance Education; 2004, 5 (2) 